\title{
Exogenous Application of Exogenous Effectors Confers Tolerance to Heavy Metals in Plants
}

ISSN: 2637-7659

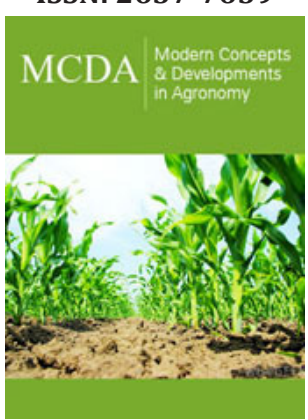

*Corresponding author: Marouane Ben Massoud, School of Biological, Earth and Environmental Sciences, University College Cork, Distillery Fields, North Mall Cork, Ireland

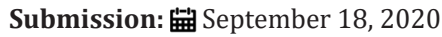

Published: 制January 06, 2021

Volume 7 - Issue 5

How to cite this article: Marouane Ben Massoud, David Sheehan, Abdelilah Chaoui. Exogenous Application of Exogenous Effectors Confers Tolerance to Heavy Metals in Plants. Mod Concep Dev Agrono. 7(5). MCDA. 000672. 2021. DOI: 10.31031/MCDA.2021.07.000672

Copyright@ Marouane Ben Massoud, This article is distributed under the terms of the Creative Commons Attribution 4.0 International License, which permits unrestricted use and redistribution provided that the original author and source are credited.
Marouane Ben Massoud ${ }^{1,2,3 *}$, David Sheehan ${ }^{2}$ and Abdelilah Chaoui ${ }^{1}$

${ }^{1}$ University of Carthage, Faculty of Sciences of Bizerte, LR18ES38 Plant Toxicology and Environmental Microbiology, 7021, Bizerte, Tunisia

${ }^{2}$ Proteomics Research Group, School of Biochemistry and Cell Biology \& Environmental Research Institute, University College Cork, Lee Maltings, Prospect Row, Mardyke, Cork, Ireland

${ }^{3}$ School of Biological, Earth and Environmental Sciences, University College Cork, Distillery Fields, North Mall Cork, Ireland

\section{Abstract}

The protective effect of exogenous effectors applications against heavy metal toxicity in plants was investigated in this mini review. The exposure of plants to heavy metals caused high metal accumulation in tissues associated with increased levels of oxidative stress biomarkers as well as enhanced antioxidant enzymes. Hence, exogenous effectors were effective in reducing heavy metals-induced toxicity by maintaining the redox cell status.

\section{Introduction}

Plants in their environment are subjected to a variety of stressful factors which generate physiological reactions leading to the formation of free radicals. These factors are divided into two groups: Biotic factors such as pathogens, bacteria and insects and abiotic factors namely salinity, certain growth substances, atmospheric pollutants, cold, UV radiation, heavy metals.

The contamination of soils by heavy metals is one of the most worrying problems today. It does not only concern the degradation of the environment, with its consequences on flora and fauna, but also represents a real public health problem by the threat of contamination of foodstuffs or by insufficient harvests [1-7]. Heavy metals that accumulate in the soil on industrial sites can be assimilated by spontaneous, replanted or cultivated vegetation. Heavy metals induce physiological and biochemical changes in plants. Indeed, several studies have made it possible to understand, in part, the course of certain defense strategies adopted by plants vis-à-vis metallic stress and to highlight biochemical and molecular modifications affecting certain physiological processes such as, lipid metabolism [6], photosynthesis [8], oxidative metabolism $[9,10]$.

High levels of heavy metals in soil as well as in water can cause:

1) Oxidative stress by accelerating the production of reactive oxygen species, high metal accumulation in tissues and lipid peroxidation [4,6], and

2) Damages in homeostasis states of ascorbate-glutathione cycle by increasing antioxidant enzyme activities such as superoxide dismutase (SOD), ferredoxin (Fdx), NADPHdependent ferredoxin reductase (FNR), thioredoxin (Trx), NADPH-dependent thioredoxin reductase (NTR), glutathione peroxidase (GPX), glutathione reductase (GR) and glutathioneS-transferase (GST) [11,12].

Plants possess various strategies to counteract the negative effects of heavy-metalinduced oxidative stress, including the exclusion of ions, the control of ion uptake and translocation to leaves, as well as the accumulation of compatible solutes (carbohydrates and proline) [13]. Additionally, to cope with oxidative stress plants have developed non-enzymatic defense system including ascorbic acid (AsA), glutathione (GSH), carotenoids and cysteine 
as well as enzymatic defense system such as superoxide dismutase (SOD), peroxidase, catalase and the enzymes of the glutathioneascorbate (GSH-AsA) cycle: ascorbate peroxidase (APX), glutathione reductase (GR), monodehydroascorbate reductase (MDAR) and dehydroascorbate reductase (DHAR) [3].

Several researchers have adopted new strategies to protect plants against abiotic stresses such as the application of exogenous effectors like auxin, gibberellic acid, calcium, citrate, nitric oxide, hydrogen disulfide [10,14-21]. Moreover, some of those exogenous effectors like calcium was shown to be involved in the signal transduction of environmental stimuli and related gene expression in plants, increasing the tolerance of plants against cadmium $[15,17]$ and $\mathrm{Cu}[20]$.

\section{Conclusion}

The biological activity of heavy metals can be markedly alleviated by the presence of metal chelators which may reverse their toxicity. Investigations indicated that exogenous effectors can reduce heavy metal toxicity by forming complex compounds with them which are then, either eliminated or unable to cross biological membranes.

\section{Acknowledgment}

This work was financially supported by the Tunisian Ministry of Higher Education and Scientific Research (LR18ES38) and Environmental Research Institute, Department of Biochemistry, University College of Cork, Ireland.

\section{References}

1. Del Rio LA, Sandalio LM, Corpas FJ, Palma JM, Barroso JB (2006) Reactive oxygen species and reactive nitrogen species in peroxisomes. Production, scavenging, and role in cell signaling. Plant Physiol 141(2): 330-335.

2. Navrot N, Rouhier N, Gelhaye E, Jacquot JP (2007) Reactive oxygen species generation and antioxidant systems in plant mitochondria. Physiol Plant 129(1): 185-195.

3. Gill SS, Tuteja N (2010) Reactive oxygen species and antioxidant machinery in abiotic stress tolerance in crop plants. Plant Physiol Biochem 48(12): 909-930.

4. Karmous I, Jaouani K, Chaoui A, El Ferjani E (2012) Proteolytic activities in Phaseolus vulgaris cotyledons under copper stress. Physiol Mol Biol Plants 18(4): 337-343.

5. Chaoui A, El Ferjani E (2013) $\beta$-Estradiol protects embryo growth from heavy-metal toxicity in germinating lentil seeds. J of Plant Growth Regul 32: 636-645.

6. Chaoui A, El Ferjani E (2014) Heavy metal-induced oxidative damage is reduced by $\beta$-Estradiol application in lentil seedlings. Plant Growth Regul 74: 1-9.
7. Sakouhi L, Rahoui S, Ben Massoud M, Munemasa S, El Ferjani E, et al. (2016) Calcium and EGTA alleviate cadmium toxicity in germinating chickpea seeds. J Plant Growth Regul 35: 1064-1073.

8. Mahjoubi Y, Rzigui T, Ben Massoud M, Kharbech O, Loussaief N, et al. (2020) Leaf Gas Exchange of Bean (Phaseolus vulgaris L.) Seedlings Subjected to Manganese Stress. Russian Journal of Plant Physiology 67: 168-174.

9. Ben Massoud M, Sakouhi L, Chaoui A (2019) Effect of plant growth regulators, calcium and citric acid on copper toxicity in pea seedlings. Journal of Plant Nutrition 42(10): 1230-1242.

10. Kharbech O, Ben Massoud M, Sakouhi L, Djebali W, Mur LAJ, et al. (2020) Exogenous application of hydrogen sulfide reduces chromium toxicity in maize seedlings by suppressing NADPH oxidase activities and methylglyoxal accumulation. Plant Physiology and Biochemistry 154: 646-656.

11. Ben Massoud M, Sakouhi L, Karmous I, Zhu Y, El Ferjani E, et al. (2018) Protective role of exogenous phytohormones on redox status in pea seedlings under copper stress. Journal of Plant Physiology 221: 51-61.

12. Karmous I, Trevisan R, El Ferjani E, Chaoui A, Sheehan D, et al. (2017) Redox biology response in germinating Phaseolus vulgaris seeds exposed to copper: Evidence for differential redox buffering in seedlings and cotyledon. PLoS ONE 12(10): e0184396.

13. Parida AK, Das AB (2005) Salt tolerance and salinity effects on plants: a review. Ecotoxicol Environ Saf 60(3): 324-349.

14. Rodriguez Serrano MR, Romero Puertas MC, Pazmino DM, Pilar S Testillano, María C Risueño, et al. (2009) Cellular response of pea plants to cadmium toxicity: cross talk between reactive oxygen species, nitric oxide, and calcium. Plant Physiol 150(1): 229-243.

15. Wang CQ Song H (2009) Calcium protects Trifolium repens L. seedlings against cadmium stress. Plant Cell Rep 28(9): 1341-1349.

16. Wu Y, Hendershot WH (2010) The effect of calcium and pH on nickel accumulation in and rhizotoxicity to pea (Pisum sativum L.) rootempirical relationships and modeling. Environm Pollut 158(5): 18501856.

17. Tian S, Lu L, Zhang J, Wang, Brown P, et al. (2011) Calcium protects roots of Sedum alfredii H. against cadmium-induced oxidative stress. Chemosphere 84(1): 63-69.

18. Gao Y, Miao C, Xia J, Luo C, Mao L, et al. (2012) Effect of citric acid on phytoextraction and antioxidative defense in Solanum nigrum L. as a hyperaccumulator under $\mathrm{Cd}$ and $\mathrm{Pb}$ combined pollution. Environ Earth Sci 65: 1923-1932.

19. Zehra A, Gul B, Ansari R, Khan MA (2012) Role of calcium in alleviating effect of salinity on germination of Phragmites karka seeds. South African J of Bot 78: 122-128.

20. Ben Massoud M, Karmous I, El Ferjani E, Chaoui A (2017) Alleviation of copper toxicity in germinating pea seeds by IAA, GA3, Ca and citric acid. J of Plant Interactions 13(1): 21-29.

21. Kharbech O, Houmani H, Chaoui A, Corpas FJ (2017) Alleviation of $\mathrm{Cr}$ (VI)-induced oxidative stress in maize (Zea mays L.) seedlings by NO and $\mathrm{H}_{2} \mathrm{~S}$ donors through differential organ-dependent regulation of ROS and NADPH-recycling metabolisms. Journal of Plant Physiology 219: 71-80. 